\title{
Correlation between $T$ Stage of the Tumor and Tumor Behavior in Locally Advanced Head and Neck Squamous Cell Carcinoma
}

\author{
Zeinab Mohammed Abdel-Hafeez Elsayed ${ }^{1}$, Mohammad Sabry Elkady ${ }^{1}$, Waleed Abd Elmmonem \\ Biomy $^{1}$, Mai Mohamed Ali Ezz El Din ${ }^{1}$, Lamiaa Moustafa Abdel Megied Mohamed Ahmed ${ }^{1}$, Nashwa El- \\ khazragy $^{2}$
}

Department of ${ }^{1}$ Clinical Oncology and Nuclear Medicine and Department of ${ }^{2}$ Clinical Pathology Faculty of Medicine, Ain Shams University

Corresponding author: Lamiaa M.Abdel Megied Mohamed Ahmed, E-mail: lamiaa.ahmed@med.asu.edu.eg, Telephone: (+2) 01001460726

\begin{abstract}
Background: Head and neck cancer (HNC) represents more than 550,000 cases annually. It accounts for 380,000 deaths every year. Despite aggressive treatment, only $35 \%$ to $55 \%$ of patients who present with locally advanced HNC remain alive and free of disease 3 years after standard curative treatment. Thirty percent to $40 \%$ of patients develop locoregional recurrences, and distant metastases occur in $20 \%$ to $30 \%$. Most recurrences appear quickly within 2 years of initial treatment and an additional $10 \%$ of patients will have evidence of distant metastases at the time of first presentation.

Purpose: To retrospectively determine the prognostic effect of $\mathrm{T}$ stage in locally advanced head and neck cancer.

Patients and Methods: This study retrospectively analyzed 40 patients diagnosed with locally advanced head and neck cancer. Patients were diagnosed by a tissue biopsy and they were staged by endoscope and CT neck or MRI neck with contrast. They received their treatment and were followed up every 3 months by CTs.

Results: We found a statistically significant correlation between T stage and both PFS and OS in HNC (95\%, CI $1.00-3.10, \mathrm{p}=0.04$ and $95 \%$ CI $1.01-2.65, \mathrm{p}=0.05$ respectively). We did not find any other statistically significant correlation between other patients' sub-groups such as age, gender, smoking, affected site, stage, lymph node infiltration, receiving induction chemotherapy, receiving radiotherapy with or without chemotherapy, and response to treatment and between PFS and OS.

Conclusion: This study confirmed that the $\mathrm{T}$ stage of the tumor is an important prognostic factor in locally advanced head and neck cancer.
\end{abstract}

Keywords: Locally advanced head and neck cancer, T stage, Prognosis.

\section{INTRODUCTION}

Incidence if head and neck cancer represents more than 550,000 cases and 380,000 deaths every year ${ }^{(1)}$. It represents 3 percent of malignancies in the United States with approximately 63,000 new cases annually and 13,000 deaths ${ }^{(2)}$. In Europe, it approximately represents 4 percent of cancer incidence with 250,000 cases an and 63,500 deaths in $2012^{(3)}$.

In Egypt a hospital based epidemiology retrospective study done in Kasr-AlAini Hospital during the period from Jan 2009 till Dec 2011. It was done on cases of laryngeal cancers revealed the mean age was $57.6+10.5$ ranging from 22 to 87 years old. Males were $93.9 \%$ while females were $6.1 \%$ and $62.4 \%$ were affected in the glottic and supraglottic regions, $20.7 \%$ transglottic regions ${ }^{(4)}$.

Squamous cell carcinomas represent nearly $90 \%$ of all head and neck cancers, arising mainly in the oral cavity but also occurring in the nasal cavity, pharynx and larynx ${ }^{(5)} . T$ stage was found to be an independent prognostic factor for local recurrence, disease free survival and overall survival ${ }^{(6)}$.

Aim: Determination of the prognostic effect of $\mathrm{T}$ stage in locally advanced head and neck cancer.

\section{PATIENT AND METHODS}

Data were retrospectively collected from forty patients with locally advanced HNSCC (stage III- IVb) treated at the department of Clinical Oncology, Ain Shams University, Cairo, Egypt from May 2009 till December 2015. Of these patients; 21 had laryngeal cancer, 9 patients had oropharyngeal cancer and 10 had hypopharyngeal cancer. Patients with laryngeal and oropharyngeal carcinoma received CCRT 66-70 Gy to the primary site, involved lymph nodes were to receive 60 to 70 Gy \& 50 Gy for areas of suspected subclinical spread 2Gy/fraction, 5 fractions/week. Concurrently with Cisplatin every 3 weeks $(100 \mathrm{mg} / \mathrm{m} 2)$ or weekly Carboplatin AUC 1.5 , according to patient's performance ECOG states and medical history of any other comorbidities. Induction TPF was allowed in locally advanced 
tumors according to the institution guidelines. For patients with hypopharyngeal carcinoma, they received induction chemotherapy: consisted of docetaxel at $75 \mathrm{mg} / \mathrm{m} 2$ on day 1 , cisplatin at 75 $\mathrm{mg} / \mathrm{m} 2$ on day 1 , and 5 -fluorouracil at a dose of $750 \mathrm{mg} / \mathrm{m} 2$ by 24 -hour continuous infusion for 5 days; two to three cycles with a 21-day interval were planned. Radiation therapy was initiated between 3 and 6 weeks after the last chemotherapy cycles, external beam radiotherapy, conformal 3D planning, 66-70 Gy to the primary site, involved lymph nodes were to receive 60 to 70 Gy \& 50 Gy for areas of suspected subclinical spread, 2GY/fraction, 5 fractions/week. Concurrent weekly carboplatin (AUC 1.5) was received.

After taking the approval of research ethics committee (EC) of Faculty of medicine, Ain Shams University to perform this study, we got consent waiver as it is a retrospective study, no intervention to be done on patients and by the time of our study most of our patients were dead.

\section{Statistical Analysis:}

Statistical Analysis Software (IBM SPSS, version 23) was used for data analysis. First, descriptive analysis for the whole sample was done using counts and percentage for categorical variable and mean + SD for quantitative variables. Univariate frequency analysis was performed using chi square test and fisher exact test for categorical variables and independent $t$ test and paired $t$ test for quantitative variables. Statistical significance was established at a p-value of less than 0.05. Statistical tests have been performed using COX regression analysis to compare the OS and PFS among these different subgroups.

\section{RESULTS}

This study was carried out in Clinical Oncology Department, Ain Shams University. Data was collected retrospectively from files of 40 patients proved to have head and neck squamous cell carcinoma of the larynx, hypopharynx, and oropharynx who were presented to Ain Shams University hospitals from May 2009 to December 2015.
Table (1): Shows the demographics.

\begin{tabular}{|l|l|c|}
\hline \multicolumn{1}{|c|}{ Variable } & \multicolumn{1}{|c|}{ Subgroup } & HNC (n=40) \\
\hline \multirow{2}{*}{ Age (years) } & Male & $\begin{array}{c}\text { mean } \pm \text { SD } \\
55.0 \pm 10.0\end{array}$ \\
\cline { 2 - 3 } Gender & Female & $30(75 \%)$ \\
\hline \multirow{2}{*}{ Smoking } & No & $10(25 \%)$ \\
\cline { 2 - 3 } & Yes & $12(30 \%)$ \\
\hline \multirow{2}{*}{ Age Group } & $\leq 50$ Years & $28(70 \%)$ \\
\cline { 2 - 3 } & $>50$ Years & $12(30 \%)$ \\
\hline \multirow{2}{*}{ Gender } & Male & $28(70 \%)$ \\
\cline { 2 - 3 } & Female & $30(75 \%)$ \\
\hline \multirow{3}{*}{ Tumor site } & Larynx & $10(25 \%)$ \\
\cline { 2 - 3 } & Oropharynx & $21(53 \%)$ \\
\cline { 2 - 3 } & Hypopharynx & $9(23 \%)$ \\
\hline \multirow{2}{*}{ Stage } & Stage III & $10(24 \%)$ \\
\cline { 2 - 3 } & Stage IV & $3(7.5 \%)$ \\
\hline \multirow{3}{*}{ T Score } & T2 & $37(92.5 \%)$ \\
\cline { 2 - 3 } & T3 & $6(15 \%)$ \\
\cline { 2 - 3 } & T4 & $25(62.5 \%)$ \\
\hline \multirow{2}{*}{ LN infiltration } & Positive & $9(22.5 \%)$ \\
\cline { 2 - 3 } & Negative & $30(75 \%)$ \\
\hline \multirow{2}{*}{$\begin{array}{l}\text { Induction } \\
\text { therapy }\end{array}$} & Yes & $10(25 \%)$ \\
\cline { 2 - 3 } CCRT & No & $6(15 \%)$ \\
\hline \multirow{2}{*}{ Chemo } & CCRH & $34(85 \%)$ \\
\cline { 2 - 3 } & RTH & $34(85 \%)$ \\
\hline \multirow{3}{*}{ Response } & Cisplatin & $6(15 \%)$ \\
\cline { 2 - 3 } & Carboplatin & $27(79 \%)$ \\
\cline { 2 - 3 } & CR & $7(21 \%)$ \\
\cline { 2 - 3 } & SD & $5(12.5 \%)$ \\
\cline { 2 - 3 } & PD & $9(22.5 \%)$ \\
\cline { 2 - 3 } & PR & $12(35 \%)$ \\
\hline
\end{tabular}

Table 1 shows the demographics. The patients had mean age of 55.0 years, with $12(30 \%)$ $<50$ years and $28(70 \%)>50$ years. Thirty-six $(72 \%)$ patients were males and 14 (28\%) females. Regarding the tumor site, 21 (53\%) of patients had laryngeal cancer, 10 (24\%) had hypopharyngeal cancer and 9 (23\%) patients had oropharyngeal cancer. Regarding staging, patients with stage III disease were 17 (42.5\%); 10 of them had laryngeal cancer, 5 had hypopharyngeal cancer and 2 with oropharyngeal cancer. For stage IV there were 23 $(57.5 \%) ; 11$ of them with laryngeal cancer, 5 with hypopharyngeal cancer and 7 with oropharyngeal cancer. Six (15\%) patients had a T2 tumor, while $25(62.5 \%)$ had a T3 tumor and $9(22.5 \%)$ had T4 tumor. Regarding lymph node infiltration; 30 $(75 \%)$ had positive nodal infiltration and 10 (25\%) did not have nodal infiltration. Six (15\%) patients with hypopharyngeal SCC were primarily treated by induction TPF 2 to 3 cycles followed by CCRT according to the primary and nodal response. Thirty-four (85\%) patients were treated with CCRT, 6 patients after induction TPF and 28 as definitive treatment, $27(79 \%)$ received cisplatin 
concurrently with radiotherapy and 7 (21\%) patients received carboplatin AUC 1.5 concurrently. Six (15\%) patients received definitive radiotherapy without chemotherapy due to sever comorbidities. As regarding response to treatment; $14(35 \%)$ patients suffered disease progression after treatment, while $5(12.5 \%)$ patients had complete response, 12 (30\%) patients had partial response and $9(22.5 \%)$ patients had stable disease.

Table (2): COX regression analysis for factors affecting OS and PFS in HNC patients (months).

\begin{tabular}{|c|c|c|c|c|c|c|c|}
\hline \multirow{2}{*}{\multicolumn{2}{|c|}{ Compared groups }} & \multicolumn{3}{|c|}{ PFS (months) } & \multicolumn{3}{|c|}{ OS (months) } \\
\hline & & $\begin{array}{l}\text { Odds } \\
\text { ratio }\end{array}$ & $95 \% \mathrm{CI}$ & $\mid \begin{array}{c}\mathbf{P} \\
\text { value }\end{array}$ & $\begin{array}{l}\text { Odds } \\
\text { ratio }\end{array}$ & $95 \%$ CI & \begin{tabular}{|c|}
$\mathbf{P}$ \\
value
\end{tabular} \\
\hline Age Group & \begin{tabular}{|l|l|}
$\leq 50$ Years \\
50 Years
\end{tabular} & 2.12 & $0.35-12.8$ & 0.41 & 0.75 & $0.13-4.6$ & 0.76 \\
\hline Gender & \begin{tabular}{|l|} 
Male \\
Female \\
\end{tabular} & 0.20 & 0.03- 1.20 & 0.08 & 0.57 & 0.09-3.51 & 0.55 \\
\hline Smoking & \begin{tabular}{|l|} 
Smoker \\
Not Smoker \\
\end{tabular} & 5.37 & $0.89-32.21$ & 0.06 & 0.93 & $0.14-5.78$ & \begin{tabular}{|l|} 
\\
0.93
\end{tabular} \\
\hline $\begin{array}{l}\text { HNSCC } \\
\text { affected } \\
\text { sites }\end{array}$ & \begin{tabular}{|l|} 
Larynx \\
Oropharynx \\
Hypopharynx \\
\end{tabular} & 0.36 & 0.04-2.84 & 0.09 & 1.09 & $0.74-1.60$ & 0.63 \\
\hline Stage & III & 4.04 & $0.36-44.6$ & 0.25 & 3.14 & $0.66-14.3$ & 0.27 \\
\hline T stage & \begin{tabular}{|l|} 
T2 \\
T3 \\
T4
\end{tabular} & 1.76 & $1.00-3.10$ & $0.04 *$ & 1.59 & $1.01-2.65$ & $0.05 *$ \\
\hline $\begin{array}{l}\mathrm{LN} \\
\text { infiltration }\end{array}$ & \begin{tabular}{|l|} 
Positive \\
Negative \\
\end{tabular} & 1.43 & $\begin{array}{l}0.26- \\
11.12 \\
\end{array}$ & 0.56 & 1.50 & $0.25-8.97$ & 0.65 \\
\hline $\begin{array}{l}\text { Induction } \\
\text { therapy }\end{array}$ & \begin{tabular}{|l|} 
Yes \\
No \\
\end{tabular} & 0.41 & $0.36-4.59$ & 0.47 & 0.01 & \begin{tabular}{|c|c|}
$0.1-0.001$ \\
\end{tabular} & 0.75 \\
\hline CCRT & \begin{tabular}{|l|} 
RTH \\
CCRT \\
\end{tabular} & 0.31 & $0.05-1.91$ & 0.208 & 0.104 & $0.10-3.90$ & \begin{tabular}{|l|} 
\\
0.63
\end{tabular} \\
\hline Response & \begin{tabular}{|l|}
$\mathrm{CR}$ \\
$\mathrm{SD}$ \\
$\mathrm{PD}$ \\
\end{tabular} & 4.87 & $2.87-8.08$ & 0.203 & 1.125 & $0.85-1.47$ & 0.40 \\
\hline & \begin{tabular}{|l}
$\mathrm{PD}$ \\
$\mathrm{PR}$
\end{tabular} & & & & & & \\
\hline
\end{tabular}

The HNC studied group was divided into different subgroups as regard the age, gender, smoking, affected site, stage, $\mathrm{T}$ stage, lymph node infiltration, receiving induction chemotherapy, receiving radiotherapy with or without chemotherapy, and response to treatment and were compared to PFS and OS as shown in Table 2. It was found that $\mathrm{T}$ stage of the tumor had a statistically significant correlation with both PFS and $\mathrm{OS}(\mathrm{OR}=1.76,95 \% \mathrm{CI}: 1.00-3.10, \mathrm{p}=0.04$ and $\mathrm{OR}=1.59,95 \%$ CI $1.01-2.65, \mathrm{p}=0.05$ respectively). We had 6 patients with T2 disease with median PFS 15.5 months and median OS 16.5 months, 25 patients with T3 disease with median PFS 10 months and median OS 14 months and 9 patients with T4 disease with median PFS 6 months and median OS 6 months. Our analysis showed that T4 disease showed the worse prognosis. Figures 1 and 2 show the Kaplan- Meier curves for PFS and $\mathrm{OS}$ according to $\mathrm{T}$ stage respectively. We did not find any other statistically significant correlation between other patients' sub-groups and PFS and OS.

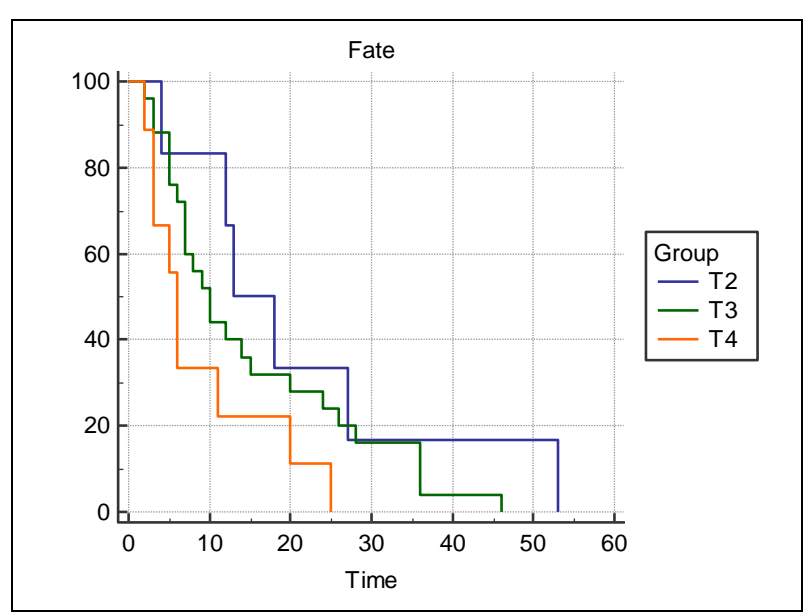

Figure (1): Kaplan-Meier survival curves for the PFS according to $\mathrm{T}$ stage.

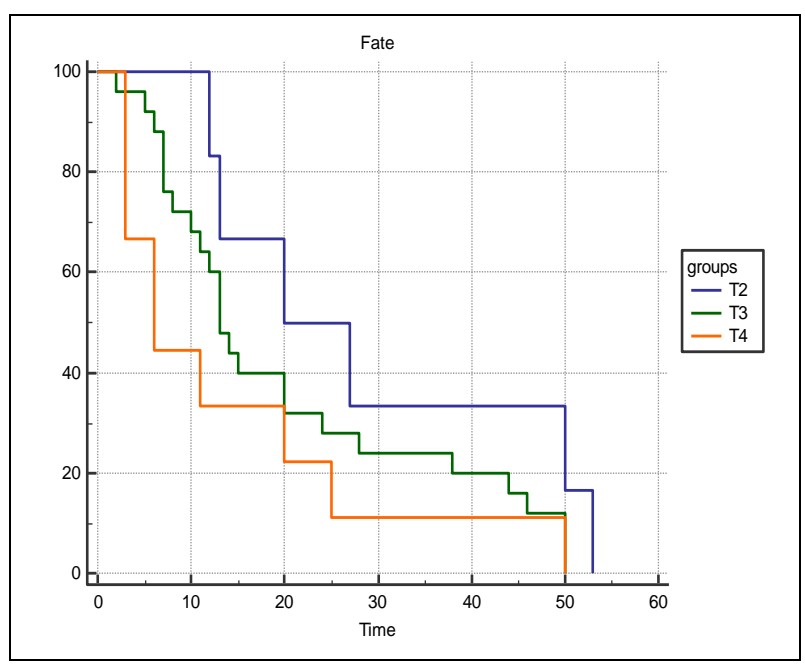

Figure (2): Kaplan-Meier survival curves for the OS according to $\mathrm{T}$ stage.

\section{DISCUSSION}

The current study showed that $\mathrm{T}$ stage of the tumor is an independent prognostic factor in locally advanced head and neck cancer. We found that there is a statistically significant correlation between $\mathrm{T}$ stage of the tumor and both PFS and OS (95\%, CI $1.00-3.10, p=0.04$ and $95 \%$ CI $1.01-2.65, p=0.05$ respectively). Our results were consistent with the work in a study done on 41 patients with advanced HPSCC who had undergone definitive concurrent chemoradiation treatment between January 2006 and October 2009 was performed; it concluded significant prognostic factors for $\mathrm{CR}$ were $\mathrm{T}$ stage, technique of radiation. $T$ stage was found to be the only significant independent prognostic factor for LRC $(\mathrm{p}=0.003)$, DFS $(\mathrm{p}=0.01)$, and OS $(\mathrm{p}=0.005){ }^{(6)}$. In a survival and prognostic analysis of 221 patients with advanced 
laryngeal squamous cell carcinoma treated by surgery, multivariate analysis showed that the postoperative pathological tumor stage was an independent factor affecting prognosis. The prognosis of glottic laryngeal carcinoma was much better than that of supraglottic carcinoma $(\mathrm{p}<0.05)$, which may be possibly due to a higher recurrence and lymphatic metastatic rate of supraglottic laryngeal carcinoma ${ }^{(7)}$. Our results were contradicting with a study done seventy-three HNC patients. They found that T stage had no prognostic value and neither affect PFS nor $\mathrm{OS}^{(8)}$. Another trial showed that $\mathrm{T}$ stage of the tumor only affected OS $(, \mathrm{p}=0.04)$ but not PFS $(\mathrm{p}=0.61)^{(9)}$.

\section{CONCLUSION}

This study confirmed that the $\mathrm{T}$ stage of the tumor is an important prognostic factor in locally advanced head and neck cancer.

\section{REFERENCES}

1. Fitzmaurice C, Global Burden of Disease Cancer Collaboration, Allen C et al. (2017): Global, Regional, and National Cancer Incidence, Mortality, Years of Life Lost, Years Lived With Disability, and Disability-Adjusted Life-years for 32 Cancer Groups, 1990 to 2015: A Systematic Analysis for the Global Burden of Disease Study. JAMA Oncol., 3: 524.

2. Siegel R, Miller KD and Ahmedin J (2017): Cáncer Statistics Ca Cáncer Journal, 67(1): 7-30.

3. Gatta G, Botta L, Sánchez MJ et al. (2015): Prognoses and improvement for head and neck cancers diagnosed in Europe in early 2000s: The EUROCARE-5 population-based study. Eur J Cancer, 51: 2130.

4. Tawab HA, Abd El Messiha MW, Al Naggarb NA et al. (2014): Study of the epidemiology and management of laryngeal cancer in Kasr Al-Aini Hospital. The Egyptian Journal of Otolaryngology, 30: 208-214.

5. Mehanna H, Paleri V, West CM et al. (2010): Head and neck cancer-Part 1: epidemiology, presentation, and prevention. BMJ., 341: c4684.

6. Krstevska V, Stojkovski I, Zafirova B et al. (2012): Prognostic factors in patients with advanced hypopharyngeal squamous cell carcinoma treated with concurrent chemoradiotherapy. Journal of BUON., 17: 327-336.
7. Liu TR, Yang AK, Chen FJ et al. (2009): Survival and prognostic analysis of 221 patients with advanced laryngeal squamous cell carcinoma treated by surgery. Chinese Journal of Cancer, 28 (3): 249-253.

8. Gasparini G, Bevilacqua $P$, Bonoldi E et al. (1995): Predictive and prognaostic markers in a series of patients with head and neck squamous cell invasive carcinoma treated with concurrent chemoradiation therapy. Clinical Cancer Research, 1:1375-1383.

9. Wachters JE, Schrijvers ML, SlagterMenkema L et al. (2013): Prognostic significance of HIF-1a, CA-IX, and OPN in t1-t2 laryngeal carcinoma treated with radiotherapy. Laryngoscope ,123: 2154-2160. 